\title{
Ultraviolet-Visible Spectrometry Characterization of Combustion in Hybrid Rocket Motors
}

\author{
Edmond W. Wilson, Jr. ${ }^{1}$, Brett D. Keller ${ }^{2}$, Kellen M. Harkness ${ }^{3}$, \\ Christopher S. Smeal ${ }^{4}$, Megan S. Easterly ${ }^{5}$ and James E. Mackey ${ }^{6}$ \\ Department of Physical Science, Harding University, Searcy, AR, 72149-0849
}

\begin{abstract}
Small, portable ultraviolet and visible spectrometers can be used to characterize the combustion and regression rates of hybrid rocket and other combustion emission plumes. In this study, two spectrometers, operating in the ultraviolet and visible ranges, were used to measure the hydroxyl radical emission spectrum and the broadband visible emission spectrum of hybrid rocket motors under a variety of oxidizer to fuel ratios. Time and spatial profiles were measured along with regression rates. Correlations were drawn between broadband emission spectra and regression rates. The distribution of hydroxyl radical concentrations was measured as a function of distance from the rocket nozzle, fuel to oxidizer ratio and time into the burn. The fuel grains used were polymethylmethacrylate, PMMA.
\end{abstract}

\section{Introduction}

COR the past several years, the focus of our research group has been the development of sensors for chemical rocket motors. ${ }^{1-5}$ Newer technological advances have made it possible for instrument builders to design and market instruments that have simpler designs and yet perform nearly as well as more expensive, general use instruments. This is especially true in the development of spectrometers. By use of sophisticated software algorithms, these newer instruments can perform tasks with fewer moving parts. Reduction in mechanical components by software and electronics leads to more compact, rugged and less expensive instrumentation. The use of holographic concave gratings and CCD linear array detectors has made it possible to construct robust, sensitive spectrometers ideal for deployment in rocketry and space missions. In this paper, we exploit the advantages of two spectrometers for use in characterization of hybrid rocket exhaust plumes. Neither of these devices has any moving parts.

Although, in principle, we could apply our sensor systems to any combustion process or any type of rocket motor, hybrid rockets are used in these studies. This is because hybrid rocket motors are becoming more important in the arsenal of available rocket propulsion systems. Space Ship One, the first manned civilian space ship to fly into space was propelled by a hybrid rocket motor using hydroxyterminated polybutadiene, HTPB, as the fuel. Several sounding rockets, such as the Black Brandt series, use hybrid rocket motors. The main reason rocket motor designers choose hybrid rocket systems is safety; the oxidizer is kept separate from the fuel grain until it is mixed in the combustion chamber. This makes the fuel easier to handle, transport and store safely. Furthermore, the motors are simpler than liquid rocket motors and have the ability to be stopped and restarted while being deployed. Solid rockets do not enjoy this important safety feature and liquid rocket motors are much more complex. Both solid and liquid rockets are deployed under stringent safety rules. Our goal is the development of optical sensors to provide information that improves the thrust and reliability of hybrid rocket motors, leads to a better understanding of the

\footnotetext{
${ }^{1}$ Professor, Department of Chemistry, Harding University, 915 East Market Street/HU 10849, Searcy, AR 721490849, Associate Member.

${ }^{2}$ Student, Department of Chemistry, Harding University, 915 East Market Street/HU 13543, Searcy, AR 721493543, Student Member.

${ }^{3}$ Student, Department of Chemistry, Harding University, 915 East Market Street/HU 11488, Searcy, AR 721491488, Student Member.

${ }^{4}$ Student, Department of Chemistry, Harding University, 915 East Market Street/HU 12926, Searcy, AR 721492926, Student Member.

${ }^{5}$ Student, Department of Chemistry, Harding University, 915 East Market Street/HU 11587, Searcy, AR 721491587, Student Member.

${ }^{6}$ Professor, Department of Engineering and Physics, Harding University, 915 East Market Street/HU 10849, Searcy, AR 72149-0849, Associate Member.
} 
combustion processes, and defines environmental effects. Also, of primary interest to us is the use of sensors to control the operation of the rockets during flight.

Polymethylmethacrylate, PMMA, was used as the fuel for several reasons. It is easy to obtain in a pure form; it is machinable, making it easy to fabricate fuel grains; it contains carbon, hydrogen and oxygen with no nitrogen and burns cleanly; no soot is formed and the chemistry is less complex; it is transparent, making it possible to observe the combustion chamber visually and spectrometrically. The formula for PMMA is given in Figure 1. The chemical

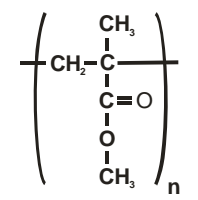

Figure 1. Chemical formula of the monomeric unit of polymethylmethacrylate, PMMA

equation for the combustion of one monomer of PMMA is given in Equation 1. As Equation 1 shows, the molar oxygen to fuel ratio is 6 to 1 .

$$
\mathrm{C}_{5} \mathrm{H}_{8} \mathrm{O}_{2}(\mathrm{~s})+6 \mathrm{O}_{2}(g) \rightarrow 5 \mathrm{CO}_{2}(g)+4 \mathrm{H}_{2} \mathrm{O}(g)
$$

\section{Experimental}

A. Spectrometers. Two compact spectrometers purchased from StellarNet, Inc. were used in these studies. Both spectrometers were calibrated by StellarNet with NIST traceable standards in order to provide accurate irradiance measurements for these studies. An EPP2000C-100 spectrometer was used to capture emission spectra in the 190 to $840 \mathrm{~nm}$ (UV/VIS/NIR) spectral range. It was constructed using a concave holographic aberration corrected grating having 590 grooves $/ \mathrm{mm}$. No light collimating or focusing mirrors were required. In this way, stray light was minimized and the dispersed radiation was presented to the detector as a flat field resulting in constant 3 $\mathrm{nm}$ resolution over the entire spectral range. There were no moving parts in the spectrometer making it both compact and rugged. The spectrometer detector was a 2048 pixel CCD. Pixel sizes were $14 \mu \mathrm{m}$ wide by $200 \mu \mathrm{m}$ tall having a $14 \mu \mathrm{m}$ pitch. A 12-bit digitizer, integral to the detector, was used for data collection. A solarization resistant $2 \mathrm{~m}$ armored $400 \mu \mathrm{m}$ fiber optic cable presented the radiation from the rocket exhaust plume to the surface of the $100 \mu \mathrm{m}$ fixed entrance slit installed in the fiber optic cable adapter. A $1 / 4$ in. CR1-mini cosine receptor for UV-VIS-NIR collected and focused the rocket emission spectra onto the fiber optic cable. A USB cable connected the spectrometer to a USB-2 port on a Hewlett Packard laptop computer. The second spectrometer, StellarNet, Model EPP2000-UV5-HR, was a high resolution unit that was factory adjusted to measure hydroxyl radical radiation in the 280 to $340 \mathrm{~nm}$ (UV) range of the ultraviolet. It was equipped with a 3600 groove $/ \mathrm{mm}$ grating and required a collimating mirror. The slit width of $25 \mu \mathrm{m}$ provided an approximate resolution of $0.12 \mathrm{~nm}$. A $1 / 2 \mathrm{in}$. CR1-UV cosine receptor for UV-Vis was required for the calibrated irradiance measurements. The detector and fiber optic cables were identical to those used by the EPP200C-100 unit. SpectraWiz Software, Version 3.3b - S30, SWupdate 4g, along with the irradiance calibration files were provided by StellarNet to make the rocket exhaust plume irradiance measurements.

B. Test Stand. Figure 2 is a photograph of the test stand used to make radiance measurements of the rocket exhaust plumes. The PMMA rocket fuel grains are mounted on a 12 in. Rack and Pinion Slide, Model U31-240 with 1/4-20, 4 in Adapter Plate, Model U53-831, from Edmund Scientific. Using this precision slide, the exhaust plume can accurately be measured at different distances from the end of the fuel grain. Adjustment is also provided for the vertical direction. Fuel grains are made by boring $6.25 \mathrm{~mm}$ holes down the middle of $102 \mathrm{~mm}$ long by $25.4 \mathrm{~mm}$ o.d. cast plexiglass rods. The holder for the UV cosine receptor was machined from a $66.0 \mathrm{~mm}$ long by $25.4 \mathrm{~mm}$ o.d. black delrin rod. A $12.5 \mathrm{~mm}$ i.d. cylinder was drilled lengthwise through the rod. When the cosine receptor is mounted in the tube, it is $57.2 \mathrm{~mm}$ from the detector to the exit hole. The distance from the end of the collimating tube to the center of the flame was $61 \mathrm{~mm}$. For the UV-VIS-NIR spectrometer, commercial components were employed. The mini cosine receptor was mounted in a half inch adapter tube that was screwed into an iris diaphragm. The iris diaphragm was screwed into a $158.75 \mathrm{~mm}$. long by $25.4 \mathrm{~mm}$ tube. This tube was terminated with another iris diaphragm. The distance from the iris diaphragm to the center of the exhaust plume was $71 \mathrm{~mm}$. Figure 3 shows a side view of the test stand during a test.

C. Oxidizer Supply. The oxidizer supply system consisted of a tank of compressed gaseous oxygen. The oxygen pressure was adjusted to the desired pressure (5.0 to $60.0 \mathrm{psig}$ ) by means of a 0 to 100 psig pressure regulator at the tank. For pressures between 5 and 30 psig, the pressure was read to the nearest 0.1 psig from a 6 in. 
Ashcroft Test Gauge, Temperature Compensated, pressure gauge. Stated accuracy of the gauge was $0.25 \%$ of full scale. Above 30 psig, pressures were read to the nearest 0.2 psig with a 4 in. ACCO Helicoid Gauge. All gas connections were secured with stainless steel Swagelok 0.25 in. or 0.125 in. fittings. Oxygen flow to the rocket motors was controlled with a 2-way, stainless steel, 0.25 in. Swagelok, Model SSDLS4, manual valve. Between the on-off manual valve and the rocket motor, a 692 by $3.2 \mathrm{~mm}$ o.d. Teflon tube connected the oxygen supply to the rocket motor. It had $1.0 \mathrm{~mm}$ by $1.09 \mathrm{~mm}$ i.d. constrictions at each end where the Swagelok fittings were attached. The nominal inside diameter of the tube was $1.45 \mathrm{~mm}$. The rocket firings were instantly terminated by sending nitrogen gas through the rocket motors immediately upon closing the oxygen supply. A 0.25 in. Swagelok Tee upstream of the oxygen on-off valve supplied the nitrogen gas by means of a Swagelok, Model SSDLS4 manual valve. Oxygen flow rates were determined by time measurements of the displacement of water from a large vessel. All determinations of the flow rates in liters per second were made in duplicate and agreed to within $\pm 0.5 \%$. See Figure 4.

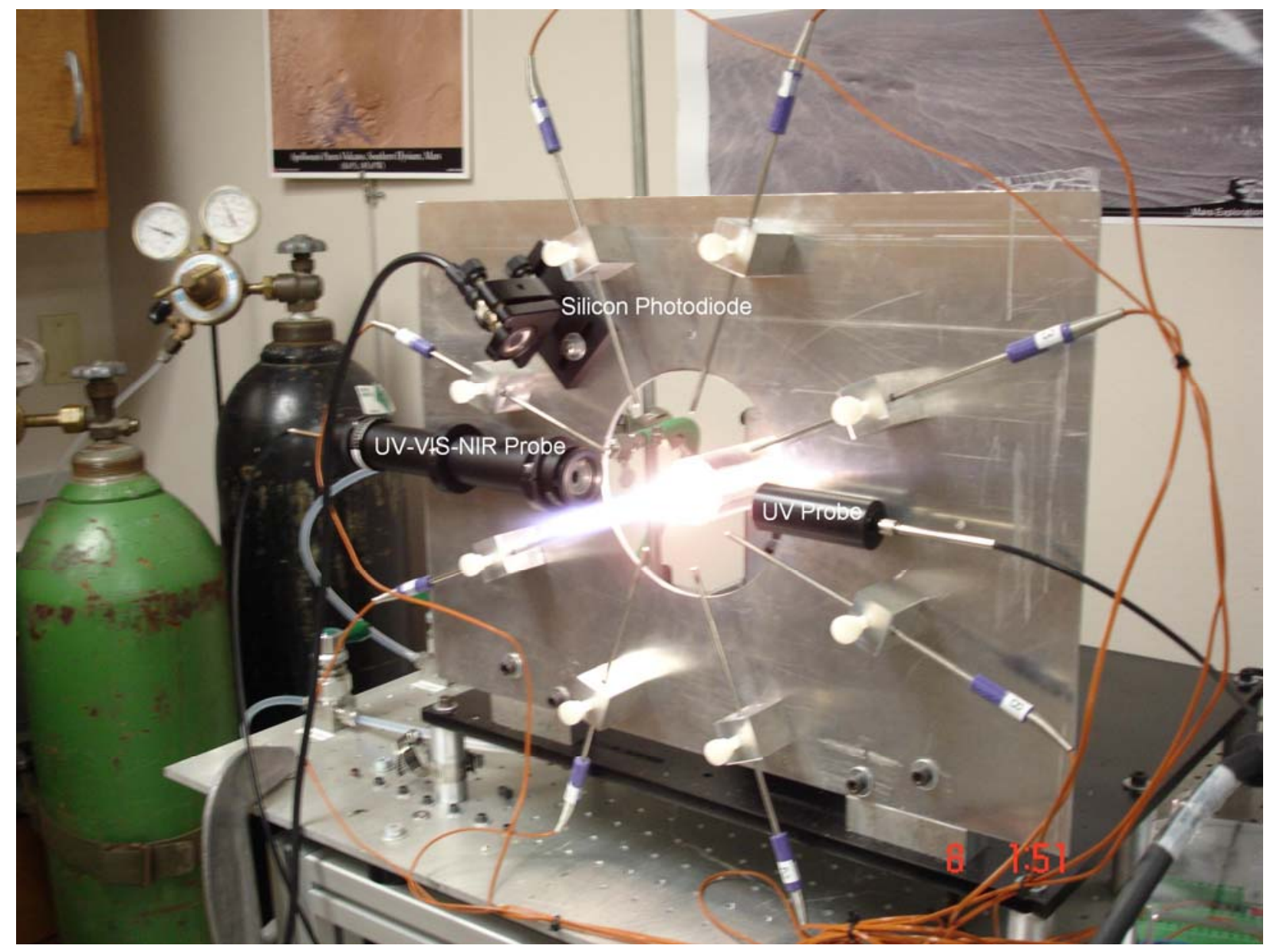

Figure 2. Rocket motor test stand used in these studies. At far left are the oxygen and nitrogen compressed gas storage tanks. The on-off valve for nitrogen is near the bottom left of the table. The test fixture holds eight thermocouples for temperature profile studies. On the left, the UV-VIS-NIR mini cosine receptor is mounted in a tube with iris diaphragms on each end. On the right is a Delrin cylinder holding the UV cosine receptor. The purpose of both tubes is to limit the field of view of the spectrometer radiance measurements. In the upper left, the silicon photodiode can be seen. The bright exhaust plume with a blue flame surrounding the inner flame is typical for emissions studied. 


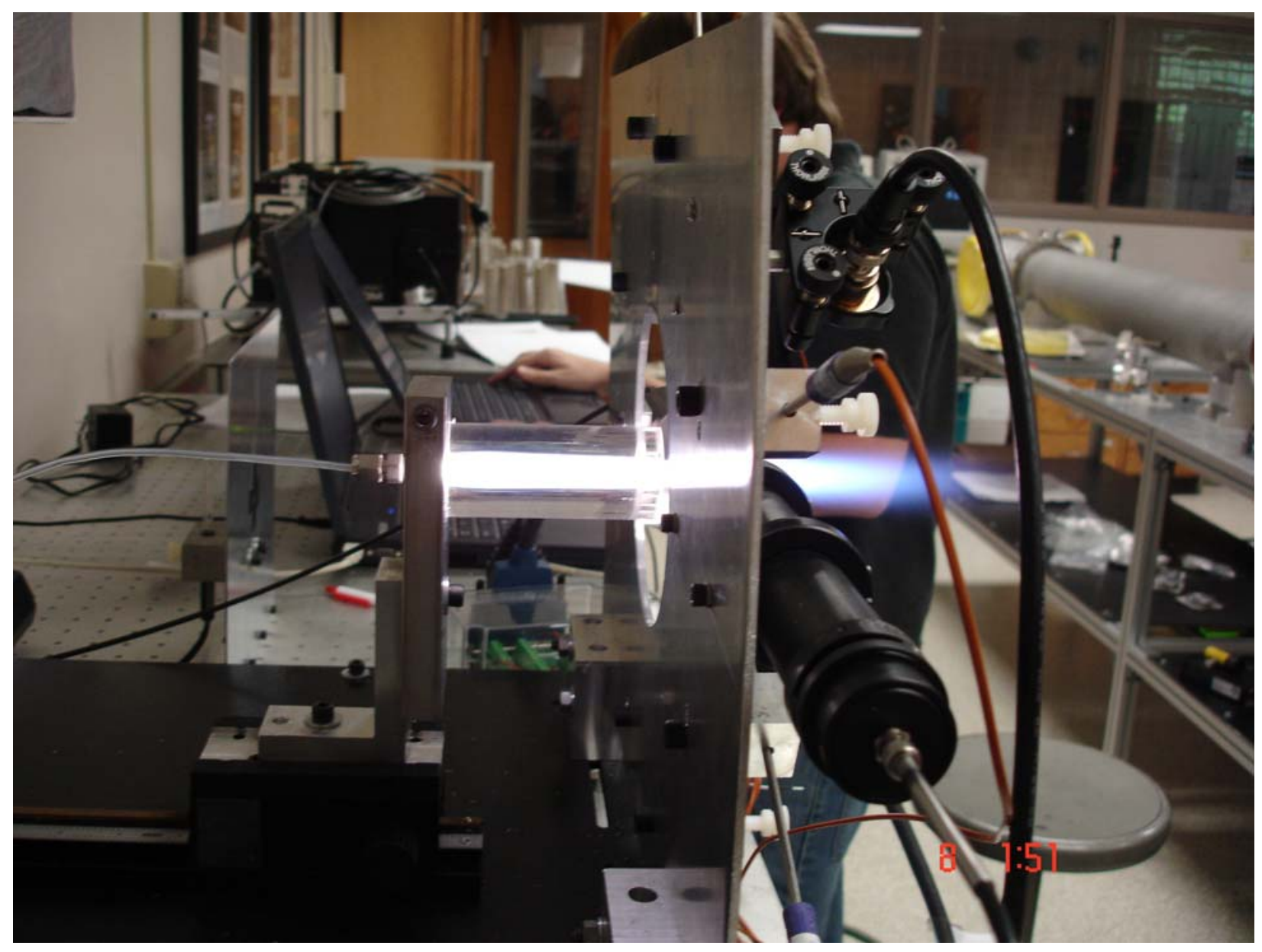

Figure 3. This photograph show a side view of the test stand during a PMMA fuel grain burn. The fuel grains are $100 \mathrm{~mm}$ long and either 25 or $37.5 \mathrm{~mm}$ in diameter. The combustion chamber is clearly visible at all times for both visual and spectrometric measurements. The characteristic blue color at the edge of the flame is believed to be due to carbon monoxide.

\section{Results}

The oxygen gas flow rate through the rocket fuel grains as a function of oxygen supply pressure was measured in duplicate and the results are reported in Figure 4. PMMA fuel consumed was found to be linear with time of motor burn. This relationship is shown in Figure 5. In order to find the correlation between grams of PMMA consumed versus combustion surface area, several spent fuel grains were cut into horizontal segments of $2.0 \mathrm{~cm}$ lengths. The diameter of the central combustion chamber was measured for each of these segments and used to calculate the average surface area of combustion. Figure 6 illustrates that the area of the combustion surface is a linear function of the mass of PMMA consumed. Figure 7 gives the relationship between total oxygen flow versus total moles PMMA consumed. As shown in Equation 1, the oxidizer to fuel ratio is 6 moles of oxygen reacted for every mole of PMMA monomer burned for stoichiometric combustion.

Figure 8 shows the shape of the PMMA fuel grain after being burned for different time periods ranging from 1050 seconds in 10 second intervals. The outside lines in the figure represent the outside diameter of $25.4 \mathrm{~mm}(1 \mathrm{in})$. The inside lines show progressive loss of PMMA as the burn time is lengthened. Figure 9 shows how the intensity of emitted radiation (irradiance) varies when placing the ultraviolet sensor at different distances from the exit end of the PMMA fuel grain. These data were obtained with the UV/VIS/NIR spectrometer. The measurements were all made for a burn time of 30 seconds at an oxygen gauge pressure of 20 psig which corresponded to an oxidizer flow rate of .011 moles per second. The vertical axis values were obtained by numerical integration of the irradiance in watts per square meter in the wavelength range of 306 to $324 \mathrm{~nm}$. Figure 10 shows the change in area under the hydroxyl radical emission peaks 


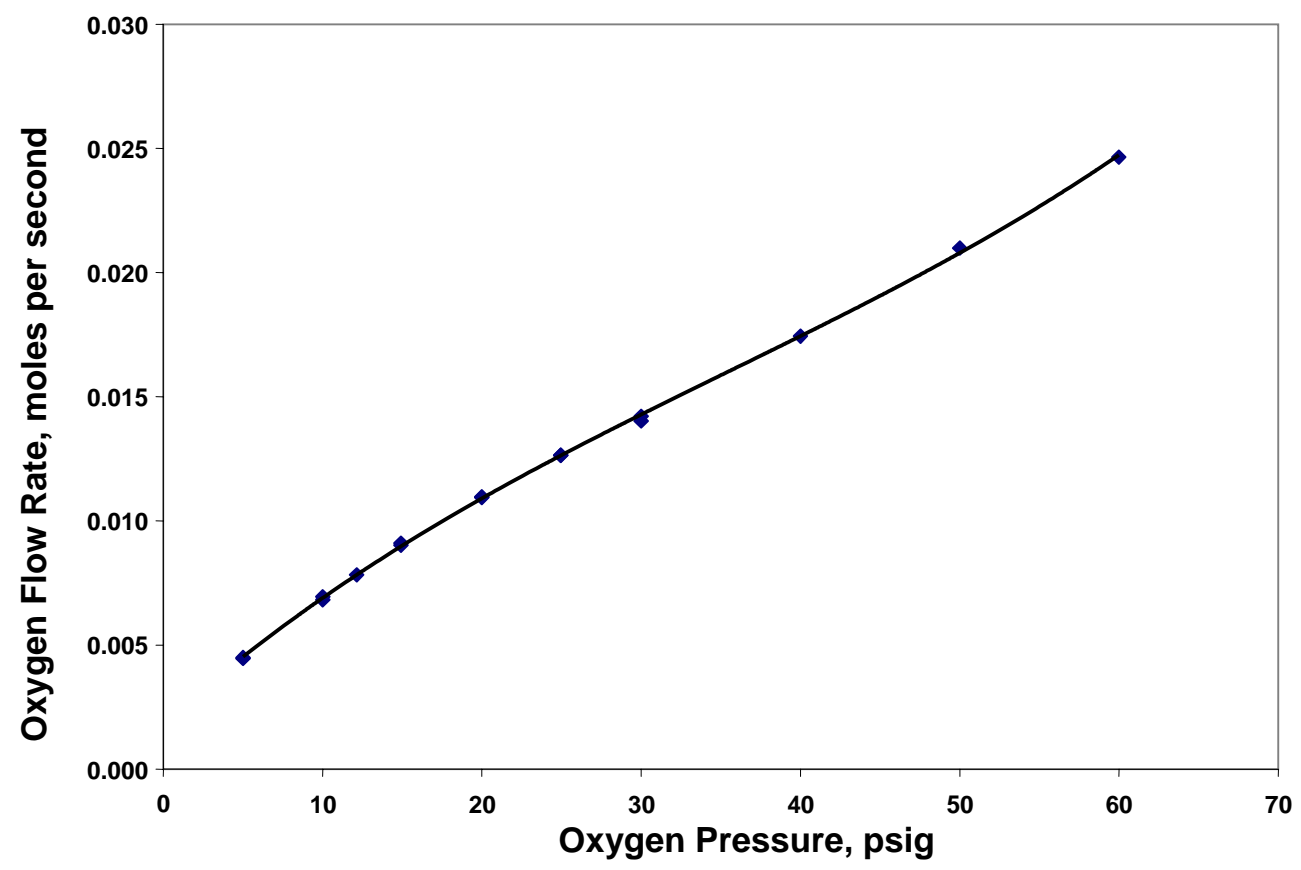

Figure 4. Oxygen flow rate through fuel grain as a function of applied oxygen pressure.

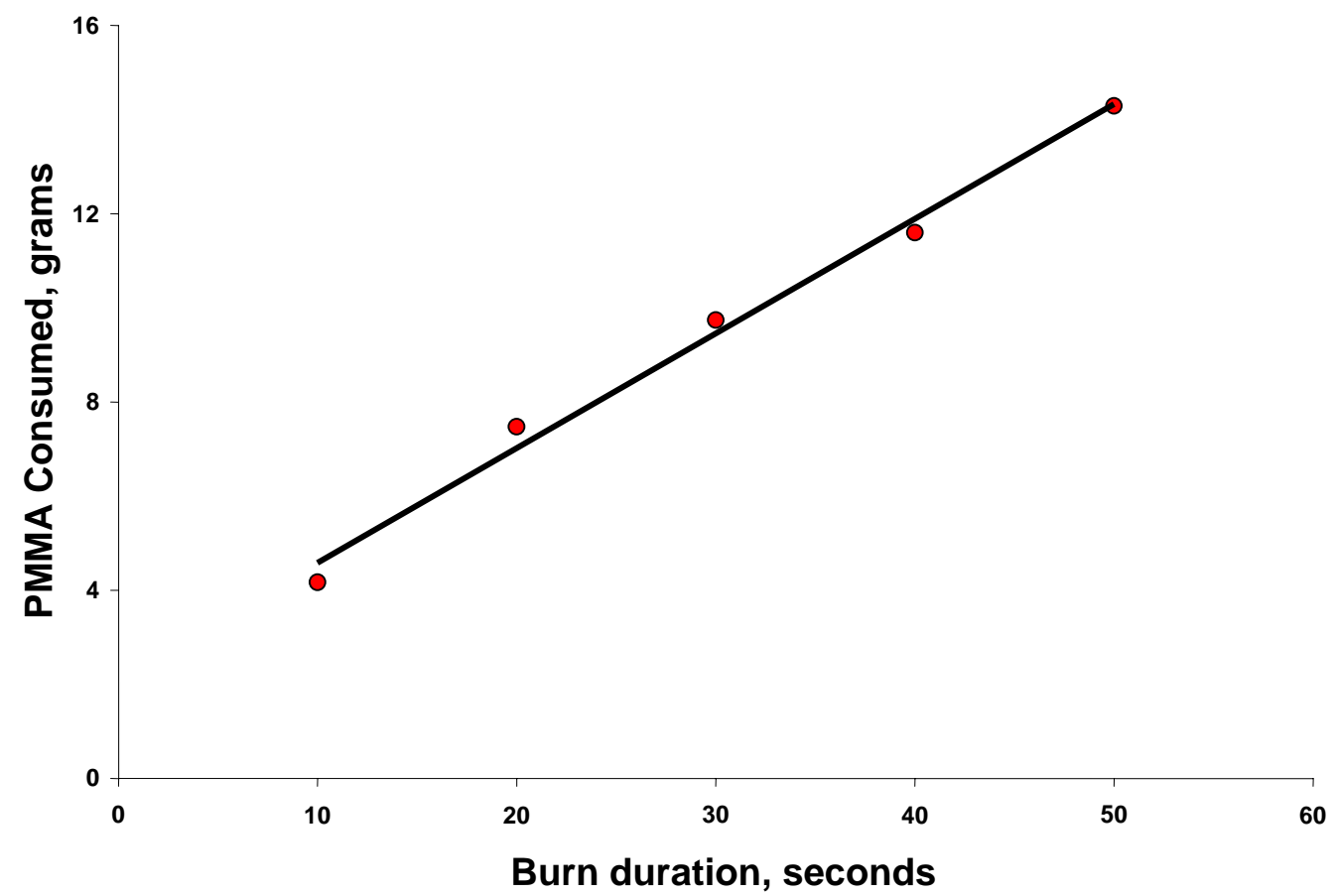

Figure 5. The grams of fuel consumed during various burn times in seconds. The oxidizer pressure was held constant at 20.0 psig. 


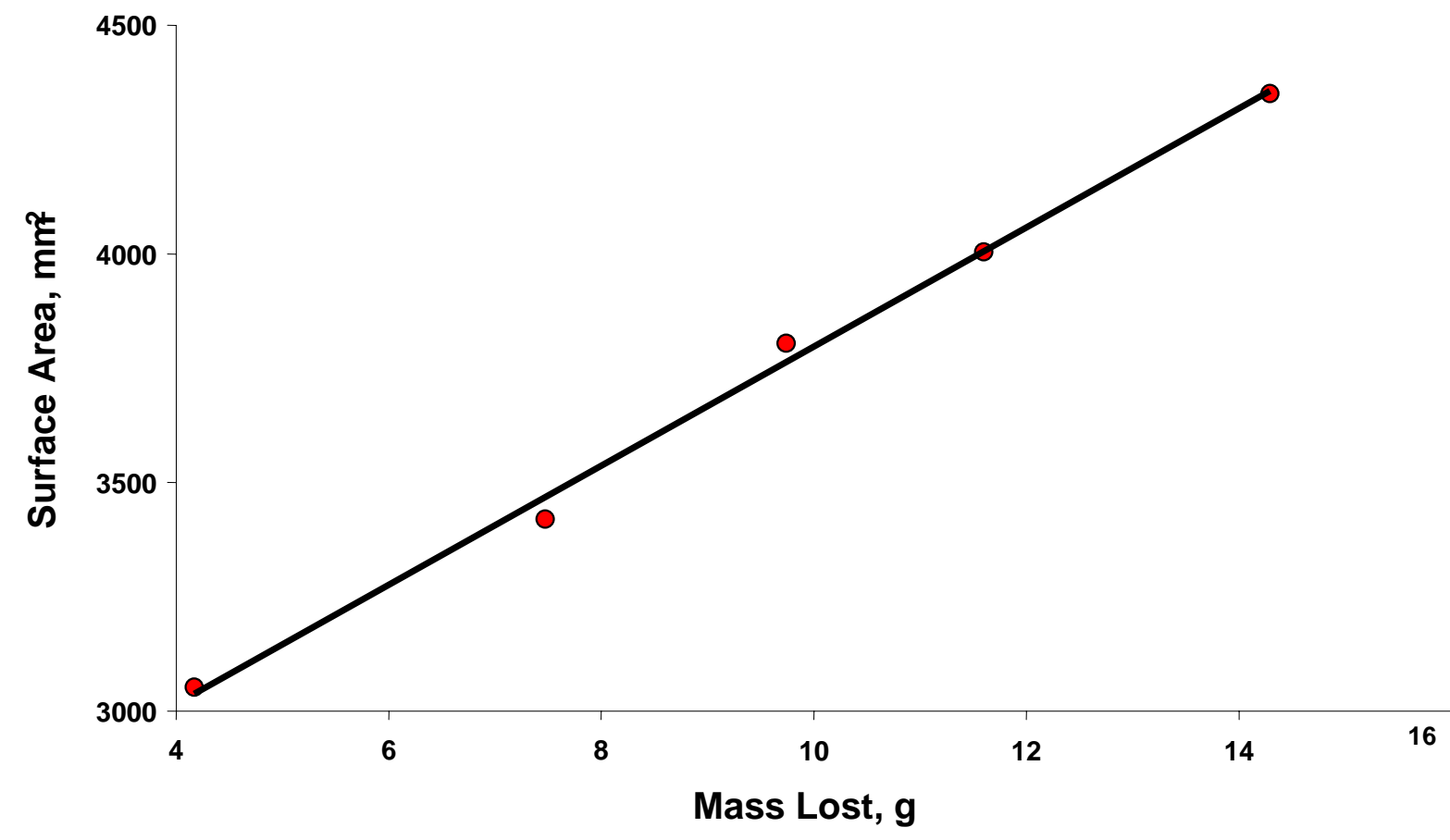

Figure 6. Combustion chamber surface area as a function of PMMA mass lost at various points in the burn.

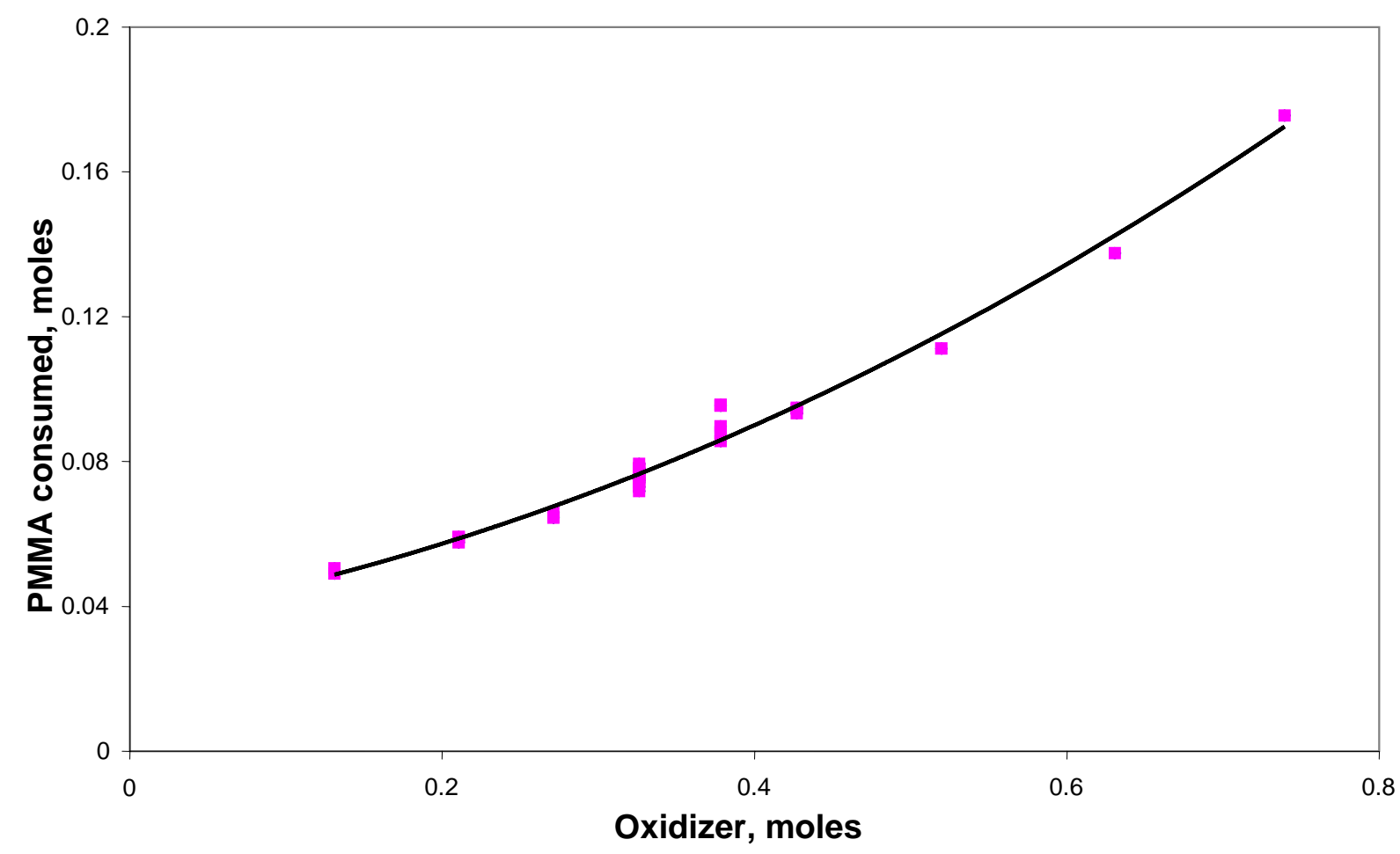

Figure 7. Ratio of moles of oxygen as a function of moles of PMMA. 


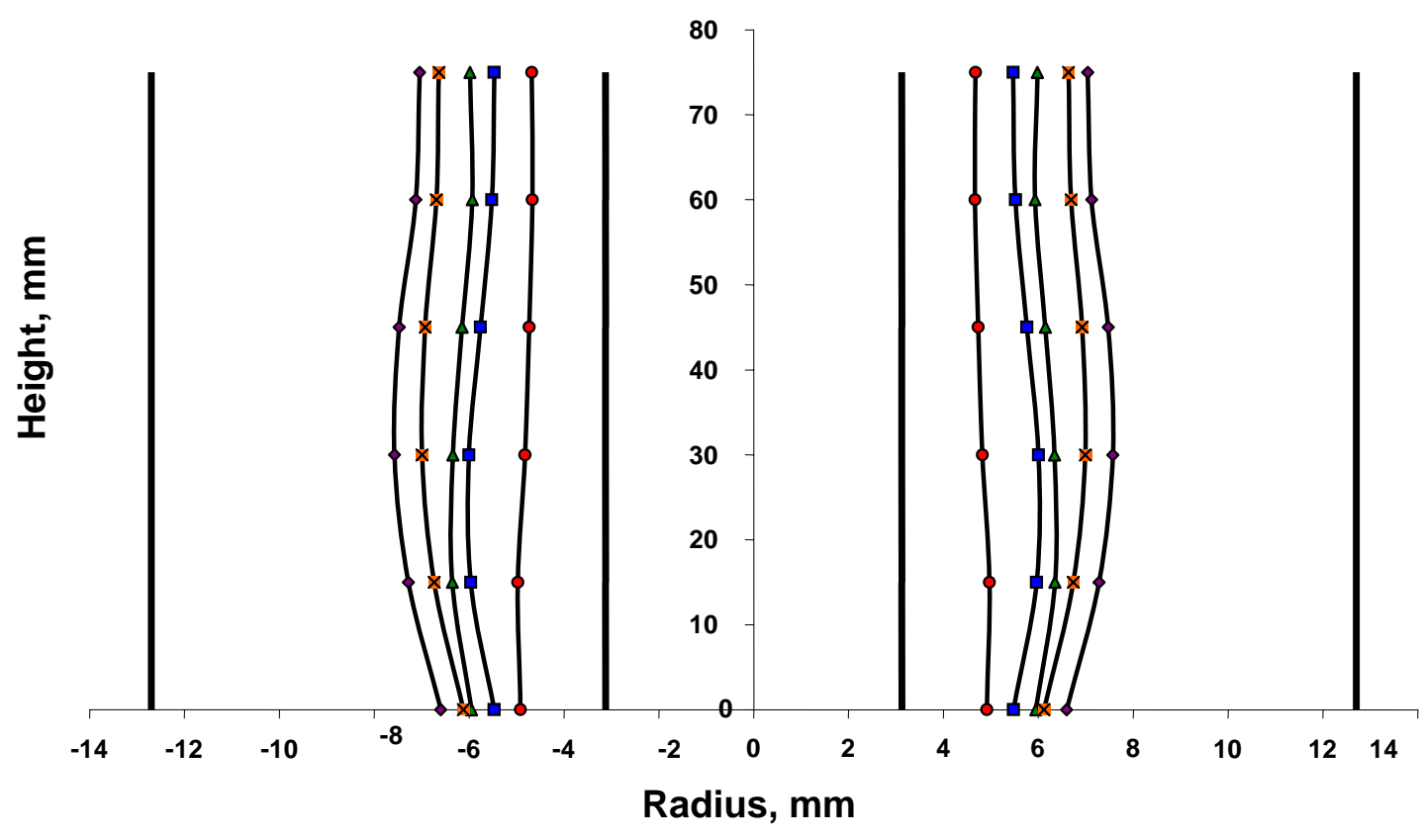

Figure 8. Surface contours of combustion chamber after rocket burns of 10-50 seconds in 10 second intervals.

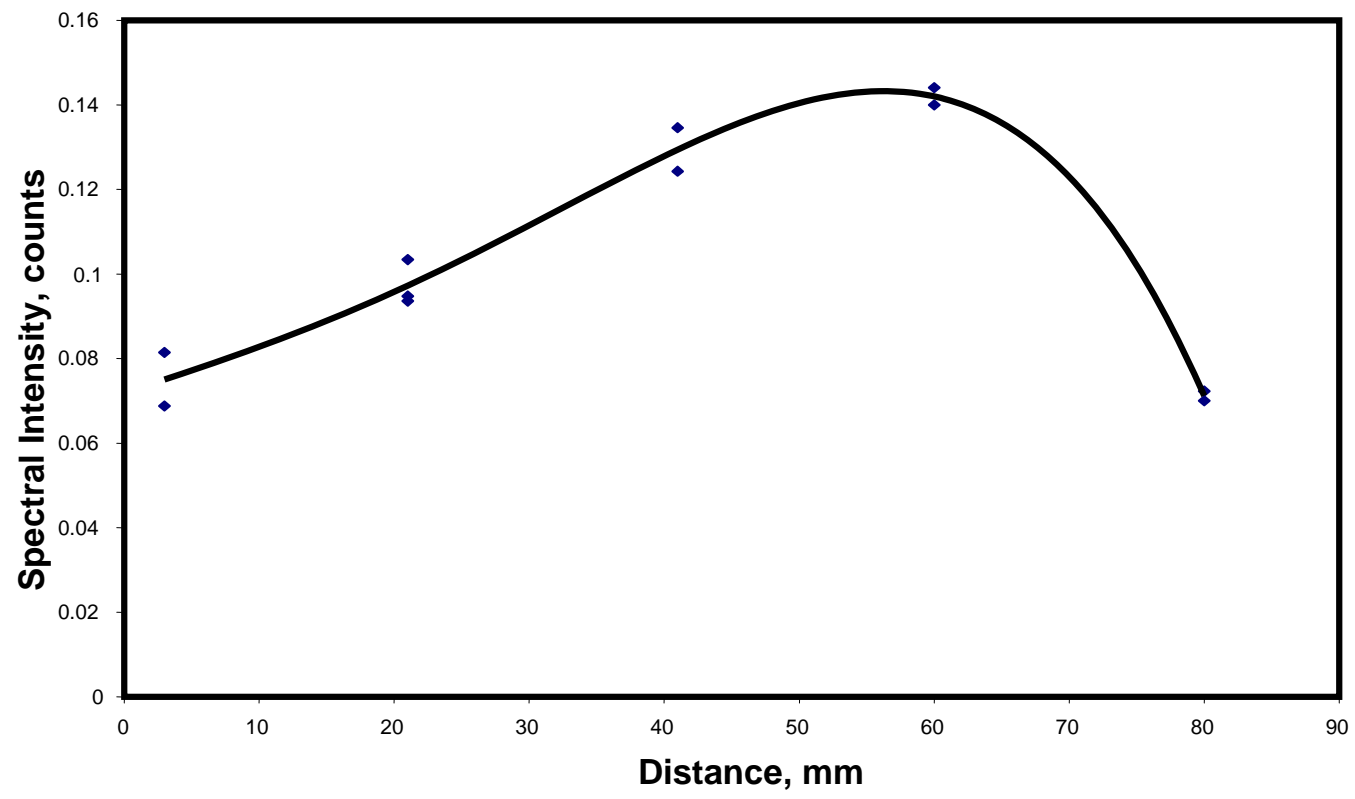

Figure 9. Spectral intensity of hydroxyl radical peak from high resolution UV spectrometer as a function of distance from nozzle. 


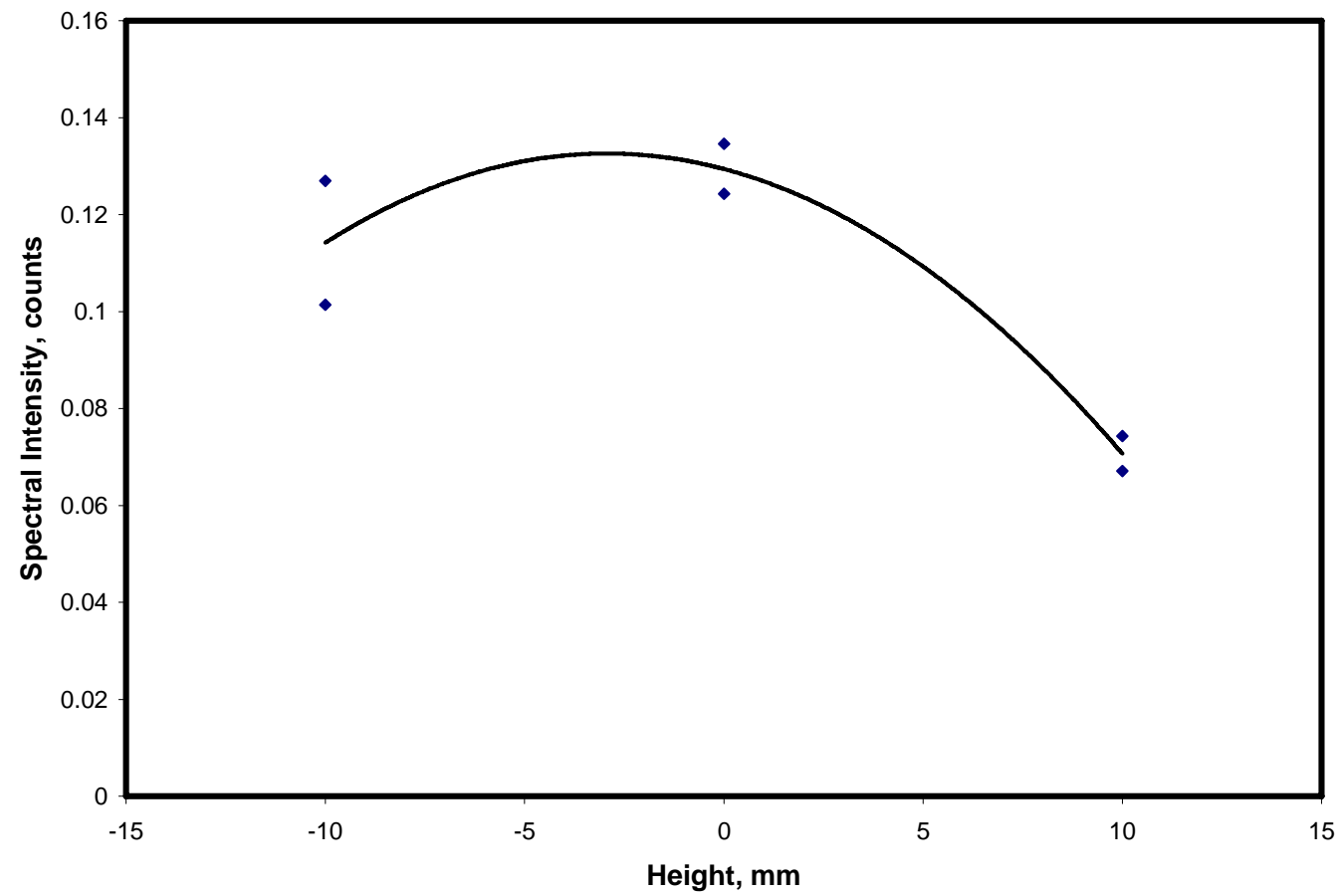

Figure 10. Spectral intensity of hydroxyl radical peak at $41 \mathrm{~mm}$ from rocket nozzle, using the high resolution UV spectrometer at three different vertical positions. This was the brightest part of the flame visually.

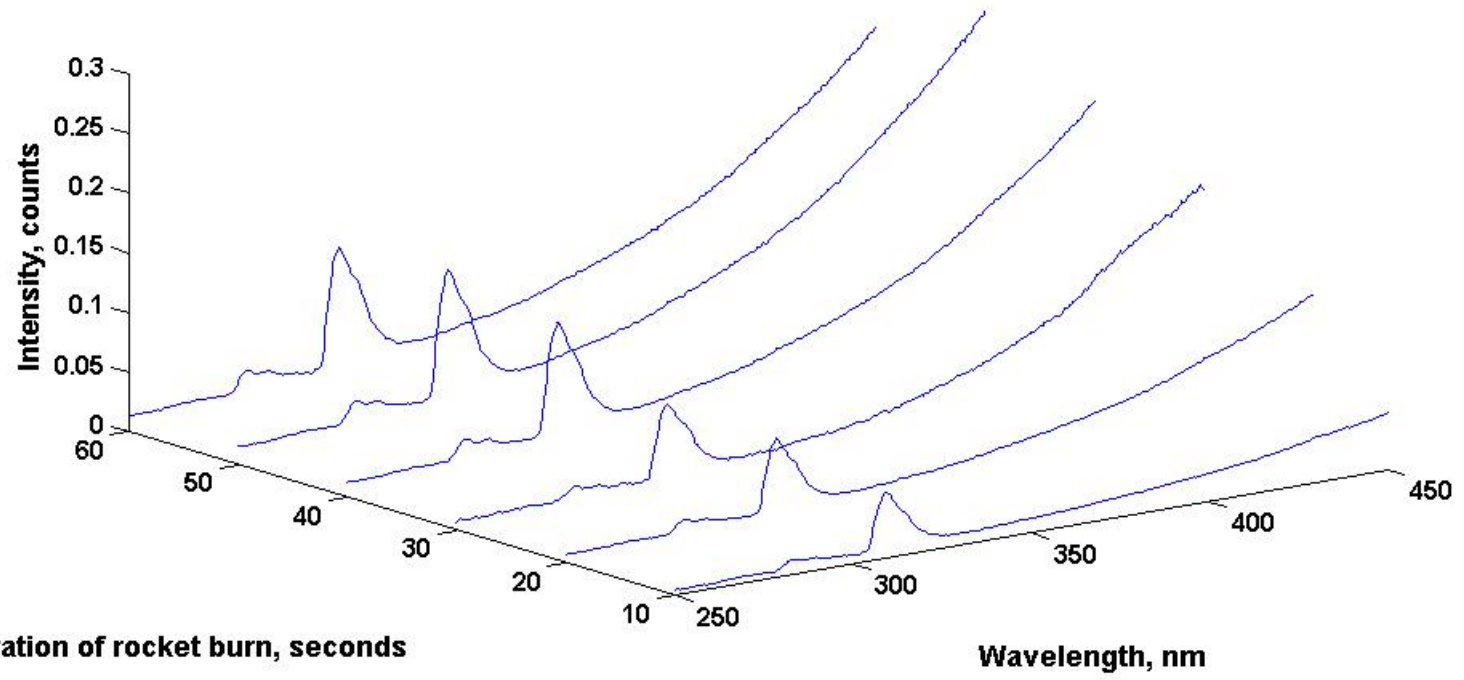

Figure 11. Spectra of hydroxyl radical region (306 to $324 \mathrm{~nm}$ ) at 10-second intervals throughout a rocket burn using UV/VIS/NIR spectrometer. 


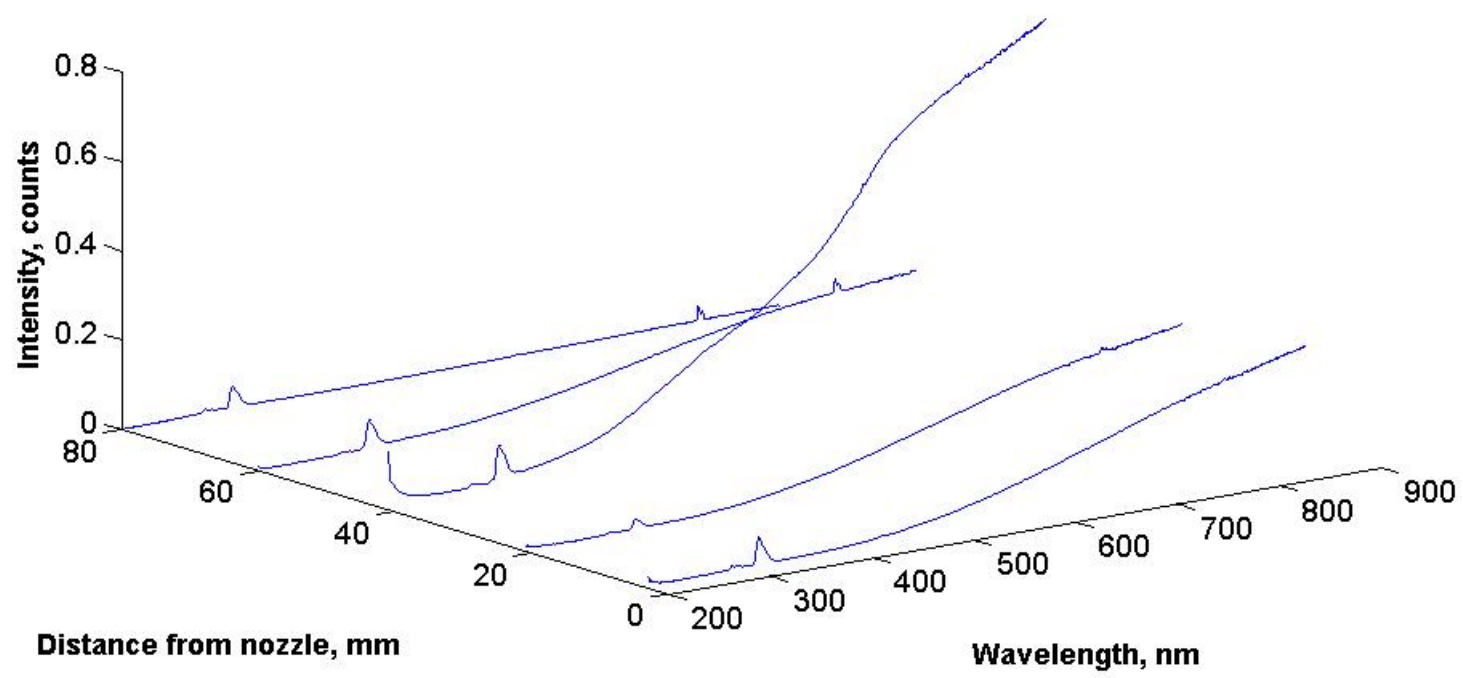

Figure 12. Spectra taken in duplicate at varying distances from the nozzle with UV/VIS/NIR spectrometer.

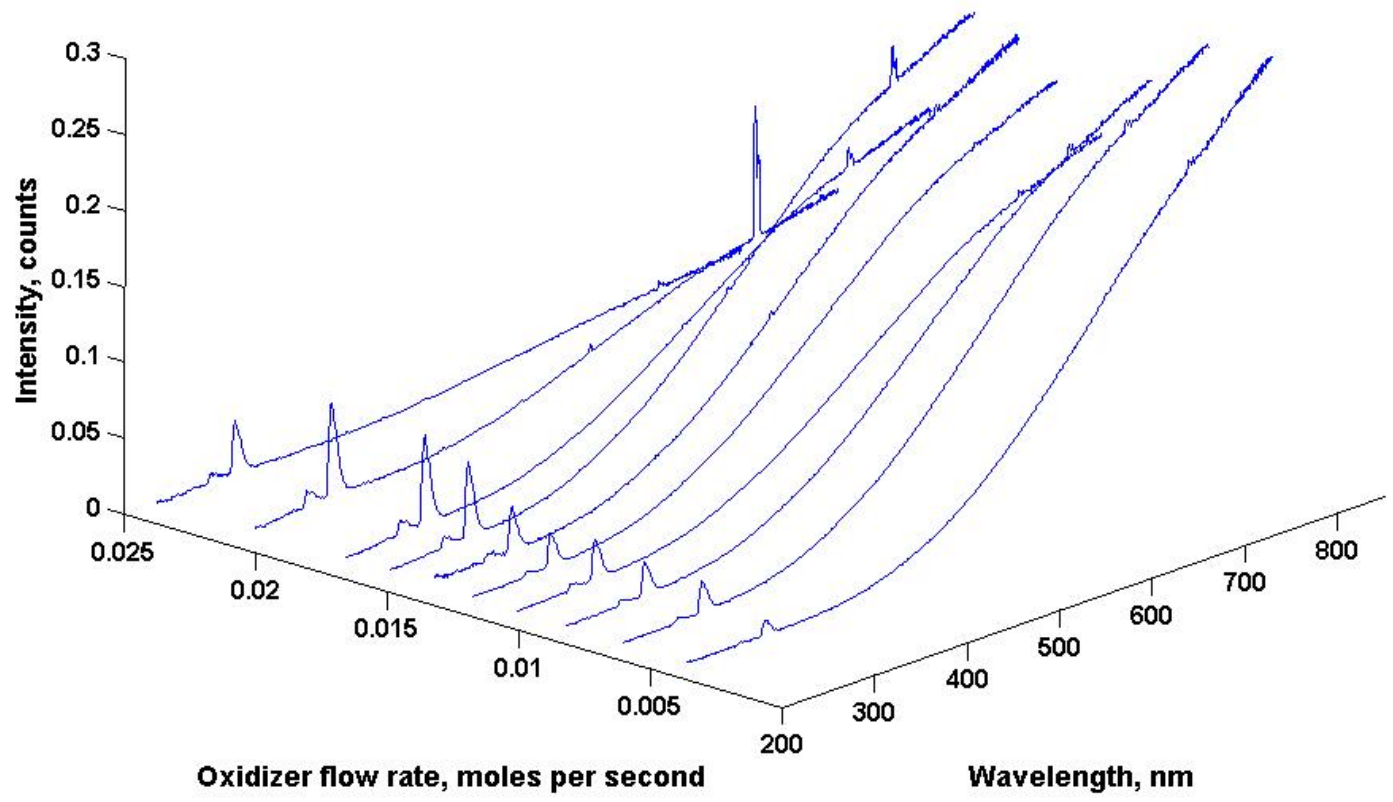

Figure 13. UV/VIS/NIR spectra taken in duplicate at various oxidizer flow rates on 30 second rocket burns using the UV/VIS/NIR spectrometer. The hydroxyl radical concentration (306 to $324 \mathrm{~nm}$ ) reaches a maximum at approximately 0.02 moles per second oxidizer flow rate. 
in the 306 to $324 \mathrm{~nm}$ range using the UV spectrometer, when measured $10 \mathrm{~mm}$ below, in the middle and $10 \mathrm{~mm}$ above the center line of the exhaust plume. These vertical distances where measured $41 \mathrm{~mm}$ from the exit end of the PMMA fuel grain. This distance corresponded to the brightest portion of the plume visually.

Figure 11 is a graph of spectra obtained by the UV/VIS/NIR spectrometer in the 250 to $450 \mathrm{~nm}$ range. Above $450 \mathrm{~nm}$ the irradiance was too high to be recorded without inserting neutral density filters into the observation path. The spectra were recorded at increasing burn times in increments of 10 seconds. Figure 12 shows spectra obtained by use of the UV/VIS/NIR spectrometer at different distances from the exit end of the burning PMMA fuel grain. Each spectrum shown is the average of two different sets of measurements. Figure 13 shows spectra obtained with the UV/VIS/NIR spectrometer at different oxidizer flow rates. The measurements were made at $21 \mathrm{~mm}$ from the exit end of the burning fuel grain. Hydroxyl radical concentration builds to a gradual peak between oxidizer flow rates of .015 and .020 moles per second.

\section{Discussion}

All measurements were made using identical cast PMMA fuel grains constructed as cylinders, $102 \mathrm{~mm}$ long by $25.4 \mathrm{~mm}$ o.d. A $6.25 \mathrm{~mm}(1 / 4 \mathrm{in})$ hole was drilled lengthwise through each fuel grain and threaded on one end to accept a stainless steel 1/8 in NPT Swagelok to $1 / 8$ in tube adapter. These fuel grains were not terminated with a nozzle or enclosed in a pressurized casing for safety reasons. By not using a nozzle, measurements were able to be made in our laboratory. Many measurements were carried out to find the capabilities of the spectrometers before attempting to characterize actual rocket motor burns at the high pressures and temperatures encountered.

The results summarized in Figure 4 show that it is possible to accurately determine the amount of oxygen delivered to the fuel grain with the apparatus developed. While the total number of moles of gaseous oxygen passed through the rocket may be determined, not all of the oxygen is necessarily involved in combustion. Figure 5 shows that the fuel grains burn at a constant rate when the oxidizer delivery is maintained at a constant level. In Figure 6 we see that the regression (weight loss) due to combustion of the fuel grain is closely correlated with area of the combustion surface. This data will be useful in determining the optimum oxidizer pressure and burn duration for the maximization of variables such as thrust and spectral intensity.

The stoichiometric ratio of oxidizer to fuel, expressed in the combustion equation (Equation 1) is 6 moles of oxygen consumed for every 1 mole of monomer burned completely to carbon dioxide and water. The tangent of the curve in Figure 7 yields the oxidant to fuel ratio. Examination of Figure 7 shows that our system never approached the ideal ratio of 6 to 1 , even when the pressure was increased to 60.0 psig. The limiting ratio we observed was approximately 4.8 to 1 moles of oxidant per mole of fuel. In real rocket motor combustion where a nozzle causes the pressure and temperature in the combustion chamber to increase, the oxidizer to fuel ratio should be greater than this, but still lower than the theoretical maximum. With the system used, it was possible to measure the surface area and contours inside the fuel grain after burning for different periods of time. Figure 8 displays the geometric history of the combustion chamber at 10 second intervals throughout the combustion process. The average combustion surface increases as a linear function of mass lost (see Figure 6). The volume closest to the oxidant source begins to form a bulge at longer burn times.

Figures 9 and 10 resulted from spectral measurements of the higher resolution $(0.12 \mathrm{~nm})$ spectrometer. The values used to make these graphs were obtained by finding the areas under the absorption peak of the hydroxyl radical from 306 to $324 \mathrm{~nm}$. Therefore, what is seen in Figure 9 is a measure of the hydroxyl radical concentration at different distances from the exit end of the PMMA fuel grain. The oxidizer pressure was held constant at $20 \mathrm{psig}$. Figure 9 indicates the maximum concentration of hydroxyl radical to be at $58 \mathrm{~mm}$ from fuel grain end under the conditions of the burn. It is interesting to note that the maximum hydroxyl radical concentration does not correspond to the visual maximum observed with the UV/VIS/NIR spectrometer. The hydroxyl maximum occurs at the flame transition between the bright white part of the flame and the blue flame tip. Figure 10 was obtained in the same manner as the data in Figure 9. It is a study of the hydroxyl radical concentration above and below the flame centerline. Because the exhaust plume is sent out horizontally, there is more heat liberated above the flame centerline than below it. Under these conditions, more hydroxyl radicals were found $1.0 \mathrm{~cm}$ below the exhaust plume centerline than $1.0 \mathrm{~cm}$ above it. In the future, the test stand will be placed so that the exhaust plume is emitted vertically. This will help to better characterize the plume by eliminating unsymmetrical effects due to gravity.

Figure 11 shows the varying intensity of both the visible range and hydroxyl radical peaks throughout a rocket burn. Intensity of the hydroxyl radical increases steadily throughout the burn. As the oxidizer flow rate stays constant and the surface area of the combustion chamber increases throughout the burn, the ratio of available fuel to available oxidizer ratio becomes more fuel-rich later in the burn. Visible spectral intensity, as seen in Figure 11, 
increases throughout the burn and may correspond to fuel-rich combustion. Figure 12 displays data taken with the UV spectrometer showing the relative intensity of hydroxyl radical and overall spectral emission at different distances from the exit end of the fuel grain. The maximum spectral intensity in the visible range is at approximately $41 \mathrm{~mm}$, which corresponds with visual observation of the brightest segment of the exhaust plume. Hydroxyl radical follows a trend similar to Figure 9, peaking between $40 \mathrm{~mm}$ and $60 \mathrm{~mm}$ from the end of the fuel grain. As noted in the discussion of Figure 9, hydroxyl radical concentration does not correspond exactly with maximum visual intensity.

The spectra shown in Figure 13 shows the presence of molecular oxygen $(763 \mathrm{~nm})$, hydroxyl radical $(280 \mathrm{~nm}$ and 306 to $324 \mathrm{~nm}$ ), and the overall visible range as a function of varying oxidizer flow rates, from .005 moles per second to .025 moles per second. The molecular oxygen peak at $763 \mathrm{~nm}$ yields reproducible, intense peaks at an oxygen flow rate of .02 moles per second. Hydroxyl radical builds to a peak between flow rates of .015 and .020 moles per second. However, overall visible intensity decreases from flow rates 0.0045 moles per second to a low at 0.011 moles per second. It increases again from .011 moles per second to .016 moles per second and then falls off rapidly as oxygen flow increases. While visible region spectral data does not show a uniform trend, it likely represents several concurrent trends. At lower oxygen flow rates, flow is smooth and leads to relatively efficient combustion. At higher flow rates the curved shape of the combustion chamber walls increases, leading to increased turbulence. Figure 11 shows hydroxyl radical concentration increasing throughout a sustained burn, likely due to more fuel rich combustion, while Figure 13 indicates an overall increase in hydroxyl radical concentration, during more oxidizer rich combustion.

\section{Conclusion}

Small, portable ultraviolet and visible spectrometers, in combination with mini-scale oxygen/PMMA hybrid rocket motors, are an ideal platform for gaining useful information about combustion processes of hybrid rocket motors. Data from the UV/VIS/NIR spectrometer produced information about hydroxyl radical and oxygen concentrations, and overall visible intensity. The higher resolution UV spectrometer provided much more detailed information on the concentrations and location hydroxyl radicals. Determination of oxidizer flow rates using gaseous oxygen was successful. An approximate oxidizer to fuel ratio was obtained.

The mass of fuel lost per burn in various conditions and measurements of diameter at different cross sections of the rocket motors provided excellent data showing the correlation of burn time, fuel consumed, and average combustion surface area. We plan to use the correlation between broadband spectral intensity in the visible region and fuel regression rate to control hybrid rocket thrust by means of a feedback loop. We will use the rocket plume irradiance to adjust oxidizer flow rate.

Clear trends in the distribution of hydroxyl radical concentrations were seen in relation to distance from the fuel grain exit end and length of time into the burn. The concentration of hydroxyl radical in relation to oxidizer flow rate is more complex, and is determined by a range of factors, including temperature, oxidizer to fuel ratio, and combustion chamber and plume spatial characteristics. Visual spectral intensity was also seen to correspond to fuel rich combustion mixtures. While visual intensity does not necessarily correlate with hydroxyl radical intensity or with combustion efficiency, further study of hydroxyl radicals may yield much usable data about the complex process of combustion.

\section{Acknowledgments}

This work was funded by NASA EPSCoR Grant, NCC5-260, Andrew Wright, Ph.D. Associate Professor of Engineering, University of Arkansas at Little Rock, PI. Christopher Smeal thanks the Arkansas/NASA Workforce Development Committee for a NASA Undergraduate Workforce Development Fellowship. Brett Keller, Kellen Harkness and Megan Easterly thank the Arkansas Space Grant Consortium for Undergraduate Research Fellowships. Brett Keller and Kellen Harkness thank NASA for EPSCoR Undergraduate Research Fellowships.

\section{References}

1. Wright, Andrew B., Teague, Warfield, Wright Ann M., and Wilson, Edmond W., Instrumentation of Labscale UALR Hybrid Rocket Motor," SPIEE, submitted March 2006.

2 Wilson, Edmond W., Jr., Mackey, James, E., Keller, Brett, D., Goertzen, Elaine, J., Clements, Sheryl A., Rivenbark, II, Charles F., and Cox, Calvin, "OH Emission Spectra of Hybrid Rocket Motors Using PMMA and HTPB," 41 AIAA/ASME/SAE/ASEE Joint Propulsion Conference, Tucson, AZ, 10-13 July 2005.

3 Sproles, Robert W., Wilson, J. Doug and Hudson, M. Keith, "Coherence of Multiple Signals in a Labscale Hybrid Rocket Motor,” AIAA 2005-3904, 41 ${ }^{\text {st }}$ AIAA/ASME/SAE/ASEE Joint Propulsion Conference, Tucson, AZ, 10-13 July 2005. 
4 Duke, D., Post, J., Mackey, J., and Wilson, Jr., E, "Virtual Open Path Diode Laser Spectrometer, AIAA 2000-3889, 36 AIAA/ASME/SAE/ASEE Joint Propulsion Conference, Huntsville, AL, 16-19 July 2000.

5 Teague, M. W., Felix, Tonya, Hudson, M. K., and Shanks, R. "Application of Hydroxyl (OH) Radical Ultraviolet Absorption Spectroscopy to Rocket Plumes," Journal of Pyrotechnics, Vol. 16, Winter, 2002, pp. 71-75. 